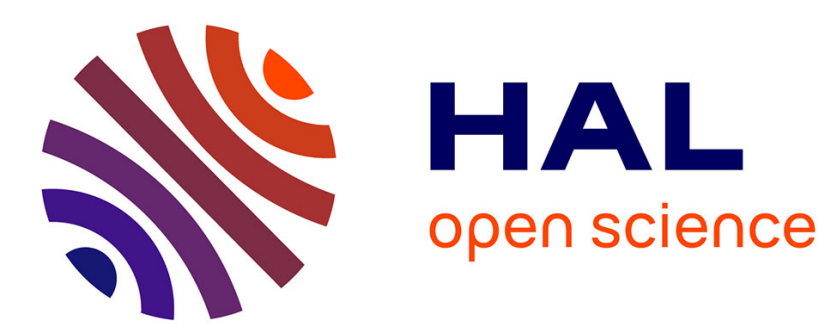

\title{
Effects of pressure and carbon dioxide, hydrogen and nitrogen concentration on laminar burning velocities and NO formation of methane-air mixtures
}

Peyman Zahedi, Kianoosh Yousefi

\section{- To cite this version:}

Peyman Zahedi, Kianoosh Yousefi. Effects of pressure and carbon dioxide, hydrogen and nitrogen concentration on laminar burning velocities and NO formation of methane-air mixtures. Journal of Mechanical Science and Technology, 2014, 28 (1), pp.377-386. 10.1007/s12206-013-0970-5 . hal01591019

\author{
HAL Id: hal-01591019 \\ https://hal.science/hal-01591019
}

Submitted on 20 Sep 2017

HAL is a multi-disciplinary open access archive for the deposit and dissemination of scientific research documents, whether they are published or not. The documents may come from teaching and research institutions in France or abroad, or from public or private research centers.
L'archive ouverte pluridisciplinaire HAL, est destinée au dépôt et à la diffusion de documents scientifiques de niveau recherche, publiés ou non, émanant des établissements d'enseignement et de recherche français ou étrangers, des laboratoires publics ou privés. 


\title{
Effects of Pressure and Carbon Dioxide, Hydrogen and Nitrogen Concentration on Laminar Burning Velocities and NO formation of Methane-air Mixtures ${ }^{\dagger}$
}

\author{
Peyman Zahedi ${ }^{1, *}$ and Kianoosh Yousefi ${ }^{1}$ \\ ${ }^{1}$ Department of Mechanical Engineering, Mashhad Branch, Islamic Azad University, Mashhad, Iran
}

(Manuscript Received 000 0, 2013; Revised 000 0, 2013; Accepted 000 0, 2013)

\begin{abstract}
In this research we have studied the effects of increasing pressure and adding carbon dioxide, hydrogen and nitrogen to Methane-air mixture on premixed laminar burning velocity and NO formation in experimentally and numerically methods. Equivalence ratio was considered within 0.7 to 1.3 for initial pressure between 0.1 to $0.5 \mathrm{MPa}$ and initial temperature was separately considered $298 \mathrm{~K}$. Mole fractions of carbon dioxide, hydrogen and nitrogen were regarded in mixture from 0 to 0.2. Heat flux method was used for measurement of burning velocities of Methane-air mixtures diluted with $\mathrm{CO}_{2}$ and $\mathrm{N}_{2}$. Experimental results were compared to the calculations using a detailed chemical kinetic scheme (GRI-MECH 3.0). At first, the results in atmosphere pressure for Methane-air mixture were calculated and it was compared with the results of literature. Results were in good agreement with published data in the literature. Afterwards, by adding carbon dioxide and nitrogen to Methane-air mixture, we witnessed that laminar burning velocity was decreased, whereas by increasing hydrogen, the laminar burning velocity was increased. Finally, the results showed that by increasing the pressure, the premixed laminar burning velocity decreased for all mixtures and NO formation indicates considerable increase, whereas the laminar flame thickness decreases.
\end{abstract}

Keywords: Burning velocity; Dilution; Heat flux; Laminar; Methane-air mixture; NO formation; Pressure

\section{Introduction}

With the depletion of crude oil reserves and the strengthening of automotive emission legislations, the use of natural gas (NG) as an alternative fuel has been promoted both in combustion engines and power generation. Natural gas contains mainly methane (typically 65-90 percent or more by volume) along with higher hydrocarbons, inert gaseous components like $\mathrm{N}_{2}, \mathrm{CO}_{2}$, water vapor and trace compounds. The composition of natural gas varies widely from one source to another in terms of the fractions of higher hydrocarbons summarized as "C2+" gases (at present vary from 7 to 16 percent) and inert gaseous components like $\mathrm{N}_{2}, \mathrm{CO}_{2}$ (at present 20-25 percent maximum). This variation of both $\mathrm{C} 2+$ and inerts is expected to widen in the future [1]. Hence interest in fuel-flexible gas turbine engines led to research on premixed combustion parameters like laminar burning velocity and ignition delay time. Fuel flexibility can impact several important premixed burner design issues such as flashback, blow off, auto ignition and stability.

Laminar burning velocities are important because they are related not only to flashback and blow off issues, but they also play a role in the stability of the flame in the combustor [2] of course it will face with some problems such as: low thermal

\footnotetext{
${ }^{*}$ Corresponding author. Tel.: +989151024207, Fax.: +985118812422

E-mail address: peimanzahedi@gmil.com

${ }^{\dagger}$ Recommended by Editor 000000 -

(C) KSME \& Springer 2013
}

efficiency or lean combustion capability [3]. The combustion of lean hydrocarbon-air mixtures offers the potential of reduced flame temperatures and $\mathrm{NO}_{\mathrm{X}}$ emissions according to the thermal mechanism. But there are two separated deficiencies in getting use of that; the first one is significant decrease of laminar burning velocity and the second one increase of incomplete combustion. Many attempts have been made to solve these two problems and one of the most effective solutions has been fuel enrichment [4]. Laminar burning velocity is important, because not only it is related to feedback of the flame and combustion, but also it plays an important role in stability of the flame in the combustion, and it is considered to be a criterion for providing the details of the reaction mechanism. Fast burning causes decrease in combustion duration, increase in thermal efficiency and decrease in fuel consumption [5].

There exist three effects of diluents on the laminar burning velocity (including dilution, thermal-diffusion, and chemical effects). The dilution effect is that, when diluent is added, the percentage of fuel and oxidant in the mixture is decreased, which decreases the laminar burning velocity. The thermaldiffusion effect is that, when diluent is added, the specific heat capacity and thermal diffusivity of the mixture vary and affect the laminar burning velocity. The chemical effect is that the 
diluent will participate in chemical reactions and affect the laminar burning velocity [6].

There are two types of methods used for determining laminar velocity: the stationary flame methods and moving flame methods. In the former category of methods, the flame front remains stationary in space, Bunsen burner method, heat flux method etc. In the latter, the flame moves with respect to some fixed point (i.e., the point of ignition): soap bubble method, constant volume method, constant pressure method etc $[7,8]$. The burning velocity directly affects the flame propagation speed and hence, the operation of the SI engine. Faster burning in SI engines leads to a more robust and repeatable combustion and permits engine operation with substantially larger amount of exhaust gas recirculation (EGR), bringing the reduction in NOx emission [9]. Enrichment of Methane fuel by hydrogen, nitrogen and carbon dioxide has been investigated by many researchers through experimental methods $[10,11]$, and the studies have indicated that laminar burning velocity of Methane-Hydrogen mixture will be increased, by increase of hydrogen fractional ratio [11, 12]. This paper is an experimental research indicating the effect of dilution of Methane-air mixture with $\mathrm{N}_{2}, \mathrm{CO}_{2}$ and also numerically with $\mathrm{H}_{2}$ on flame burning velocity. Also the effect of pressure has been identified in these diluted mixtures. Moreover, NO formation under these different conditions has been investigated numerically.

\section{Experimental Setup}

The Heat Flux method for the stabilization of adiabatic premixed laminar flames on a flat flame burner has been proposed by Bosschaart et al. [13]. This method was extensively used for measuring laminar burning velocities of gaseous fuels [14-16] and has recently been extended towards liquid fuels [17]. The designed burner is consisting of three separated parts which are overlapped on each other and have formed one unique burner. These three parts are as the following: Burner Head, Burner Plate and Plenum chamber as shown in Fig. 1. The brass burner plate $(3 \mathrm{~mm}$ of thick) on which the flame is stabilized is a perforated disc with a hexagonal pattern of $0.5 \mathrm{~mm}$ diameter holes with $0.7 \mathrm{~mm}$ pitch as shown in Fig. 2. It has been shown that this kind of pattern stabilizes a flat flame on the burner [18].

An essential ingredient in the heat flux method is the attachment of thermocouples to the burner plate to determine the temperature distribution. Five K-type thermocouples of $0.4 \mathrm{~mm}$ wire were attached into selected holes using special glue on perforated plate on the upstream side. The thermocouples were positioned at different radii and different circumferential locations to measure the temperature profile on the burner plate. The upper half of the burner head has a heating jacket and a Teflon insulation ring that separates it from the lower half with cooling jacket. The burner head has a heating jacked supplied with thermostatic water to keep the temperature of the burner plate constant. The heating jacket, water temperature was maintained at $358 \mathrm{~K}$ and the plenum chamber has a separate cooling system supplied with water at room temperature (around $307 \mathrm{~K}$ ). This fixes the initial temperature of the fresh gas mixture. The heating jacket keeps the burner plate edges at a certain temperature higher than the initial gas temperature, thus warming up the (unburned) gases flowing through. Conductive heat transfer of the flame to the burner plate cools the gas flow on its turn. If the flame is stabilized under sub-adiabatic conditions, the gas velocity is lower than the adiabatic flame burning velocity and the sum of the heat loss and heat gain is higher than zero. Then, the center of the burner plate is hotter than the heating jacket. If the unburned gas velocity is higher than the adiabatic burning velocity (super-adiabatic conditions), the net heat flux is lower than zero and the center of the burner plate is cooler than the heating jacket.

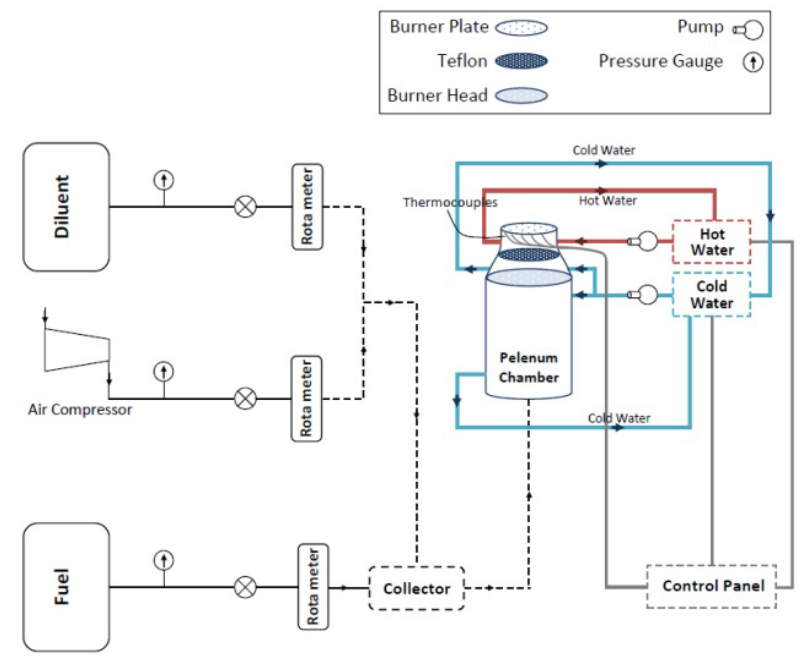

Fig. 1. Schematic of heat flux set up.

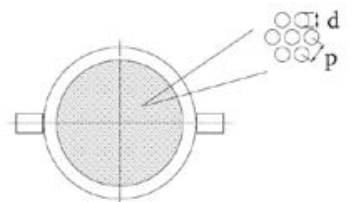

Fig. 2. Burner plate with a hexagonal pattern with $d=0.5 \mathrm{~mm}$ and $\mathrm{P}=0.7 \mathrm{~mm}$.

By varying the flow rate of the gas mixture, an appropriate value of gas velocity could be found where net heat flux is zero. This will manifest in the form of uniform radial distribution of temperature. The flow velocity at which the net heat flux is zero is shown to be adiabatic burning velocity. The temperature distribution of the burner plate is measured with the thermocouples attached to it and radial temperature profile of the plate obtained by solving the energy Eq. (1)

$$
T_{p}(r)=T_{\text {center }}-\frac{q}{4 \lambda x_{p}} r^{2}
$$


Here $T_{p}$ is the temperature profile across the burner plate, $T_{\text {center }}$ is the plate center temperature, $q$ is the net heat flux into the plate, $\lambda$ is the thermal conductivity of burner plate, $x_{p}$ is the plate thickness and $r$ is the radial coordinate. Eq. (1) is expressed in the following general form:

$$
T_{p}(r)=T_{\text {center }}+a r^{2}
$$

The coefficient $a$ depends on the unburned gas velocity $v$. By plotting $a$ against $v$, the adiabatic burning velocity $S_{L}$ can be found by interpolation to $a=0$, as described by Bosschaart [12].

\section{Numerical Method}

The PREMIX code [19] was used to calculate laminar flame velocities and to compare to our experimental results. PREMIX uses a hybrid time integrating/ Newton iteration technique to solve the steady state mass, species and energy conservation equations and can simulate the propagating flame. Equations were solved by using the TWOPNT, a boundary value problem solver in the CHEMKIN package [20].

One of the critical elements for simulation is the proper reaction mechanism that can describe the essential fundamental reaction paths followed by the overall reaction. The chemical kinetic mechanism used is the GRI-MECH mechanism. GRI-MECH is an optimized detailed chemical reaction mechanism for the calculation of natural gas chemical reaction process and the latest version is GRIMECH 3.0 [21]. GRI-MECH 3.0 consists of 325 elementary chemical reactions with associated rate coefficient expressions and thermo chemical parameters for 53 species. It includes the detailed combustion reaction mechanism for hydrogen. The ranges of GRI-MECH 3.0 are $1000-2500 \mathrm{~K}$ in temperature, 10 Torr to $10 \mathrm{~atm}$ in pressure and 0.1-5.0 in equivalence ratio. The initial flow rate of the unburned mixture was chosen equal to $0.04 \mathrm{~g} / \mathrm{cm}^{2} \mathrm{~s}$, according to the measurement of stoichiometric methane/air flame speed by Egolfopoulos et al. [22]. To start the iteration the temperature profile estimation obtained by Van Maaren et al. [14] for a stoichiometric methane/air flame was adopted, as suggested by Uykur et al. [23]. The temperature profile resulting from the first simulation step was used for the next step. At the inlet boundary temperature (298 K), pressure $(0.1,0.3$ and $0.5 \mathrm{MPa})$ and composition of the unburned mixture were assigned. At the exit boundary it was specified that all gradients vanish. It is observed that by using adaptive grid parameters GRAD $=0.02$ and CURV $=0.1$, the burning velocity obtained is grid independent. Hydrogen mole fractions, nitrogen and carbon dioxide (from 0 to 20 percent) with other components existing in unburned mixtures of HydrogenMethane/air, Nitrogen-Methane/air and Carbon DioxideMethane/air will be estimated. The length of calculations have been regarded $2 \mathrm{~cm}$ before the spot of reaction or generally equal to $12 \mathrm{~cm}$. The conservation of mass is expressed by the general continuity equation [10]:

$$
\frac{\partial \rho}{\partial t}+\nabla \cdot(\rho u)=0
$$

Where, $\rho$ is the mixture mass density and $u$ is the gas mixture velocity. The conservation of momentum, with no body forces other than gravity, is covered by

$$
\frac{\partial \rho}{\partial t}+\nabla \cdot(\rho u u)=\nabla \cdot \Pi+\rho g
$$

Where $\Pi$ is the stress-tensor and $g$ is the acceleration due to gravity. The stress-tensor consists of a hydrodynamic and viscous part: $\Pi=-p I+\tau$, in which $p$ is the pressure, $I$ the unit tensor and $\tau$ the viscous stress-tensor. The equation describing the conservation of energy is written in terms of specific enthalpy $h$,

$$
\frac{\partial \rho h}{\partial t}+\nabla \cdot(\rho u h)=\frac{\partial p}{\partial t}+u . \nabla p+\tau:(\nabla u)-\nabla \cdot q
$$

Where $q$ is the total heat flux. The term $\tau:(\nabla u)$ represents the enthalpy production due to viscous effects. When chemical reactions are to be considered, conservation equations for the species mass fractions $Y_{i}$ are used. They are defined as $Y_{i}=\rho_{i} / \rho$ with $\rho_{i}$ the density of species $i$. The density of the mixture $\rho$ is related to the density of the various species by

$\rho=\sum_{i=1}^{N_{s}} \rho_{i}$

with $N_{s}$ the number of species. This leads to a conservation equation for every species mass fraction in the mixture [10]:

$\frac{\partial \rho Y_{i}}{\partial t}+\nabla \cdot\left(\rho u Y_{i}\right)+\nabla \cdot\left(\rho U_{i} Y_{i}\right)=\dot{\omega}_{i}, \quad i \in\left[1, N_{s}\right]$

With $U_{i}$ is the diffusion velocity of species $i$. The chemical source term $\dot{\omega}_{i}$ in this equation, is characteristic for the reactive nature of the flow. Note that Eq. (7) together with the continuity Eq. (3) gives an over-complete system, so instead of $N_{s}$ only $N_{s}-1$ equations in Eq. (7) have to be solved. The mass fraction of one of the species can be computed using the following constraint:

$$
\sum_{i=1}^{N_{s}} Y_{i}=1
$$

An abundant species, e.g. nitrogen, is commonly chosen for this species. By definition chemical reactions are mass conserving, so therefore the following relations hold:

$$
\begin{aligned}
& \sum_{i=1}^{N_{s}} \rho Y_{i} U_{i}=0 \\
& \sum_{i=1}^{N_{s}} \dot{\omega}_{i}=0
\end{aligned}
$$

Finally, state equations are needed to complete the set of differential equations (4) - (7). The first state equation introduces the specific enthalpy $h$ as a function of temperature $\mathrm{T}$. This relation is given by 


$$
h=\sum_{i=1}^{N_{s}} Y_{i} h_{i} \quad \text { with } \quad h_{i}=h_{i}^{r e f}+\int_{T^{r e f}}^{T} c_{p_{i}}(T) d T
$$

And holds for perfect gases. In this equation $h_{i}$ represents the enthalpy of species $i$ and $h_{i}^{\text {ref }}$ the formation enthalpy of species $i$ at a reference value for the temperature $T^{\text {ref }}$ and $c_{p_{i}}$ the specific heat capacity at constant pressure of species $i$. The mixture heat capacity is defined by

$$
c_{p}=\sum_{i=1}^{N_{s}} Y_{i} c_{p_{i}}
$$

The species heat capacity $c_{p i}$ is commonly tabulated in polynomial form. In most combustion problems the mixture and its components are considered to behave as perfect gases. The ideal-gas law relates the density, temperature and pressure to each other by

$$
\rho=\frac{p \bar{M}}{R T}
$$

With $R$ the universal gas constant and $\bar{M}$ the mean molar mass. This $\bar{M}$ can be determined from

$$
\bar{M}=\left(\sum_{i=1}^{N_{s}} \frac{Y_{i}}{M_{i}}\right)^{-1}
$$

Where $M_{i}$ is the molar mass of species $i$.

\section{Validation of Experimental Setup}

In this section, initial experiments done on methane-air and to validate the experimental facility built are presented. There is literature abundant available on unstretched laminar burning velocity of methane for validation of the setup [24-27].

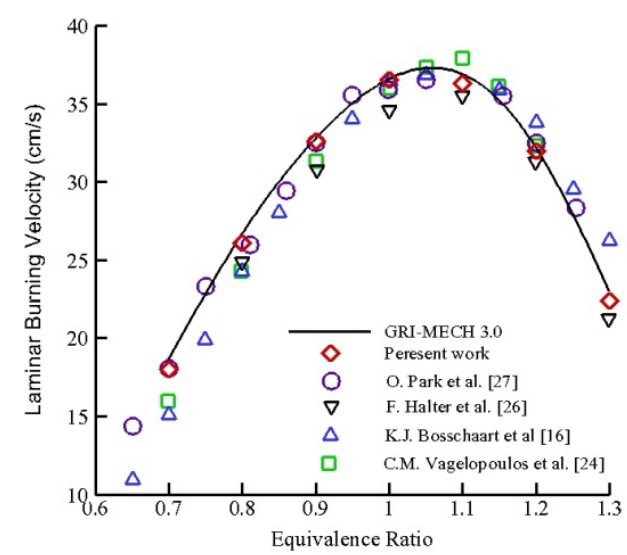

Fig. 3. Laminar burning velocities plotted versus equivalence ratio for $\mathrm{CH} 4 /$ air mixtures at $\mathrm{P}_{\text {ini }}=0.1 \mathrm{MPa}$ and $\mathrm{T}_{\text {ini }}=298 \mathrm{~K}$. Line represent calculations with CHEMKIN and Symbols represent experimental data.

The present experimental and numerical results of adiabatic burning velocities of methane-air are plotted in Fig. 3, some experimental data of previous studies are mentioned in this figure which have been conducted in different methods.
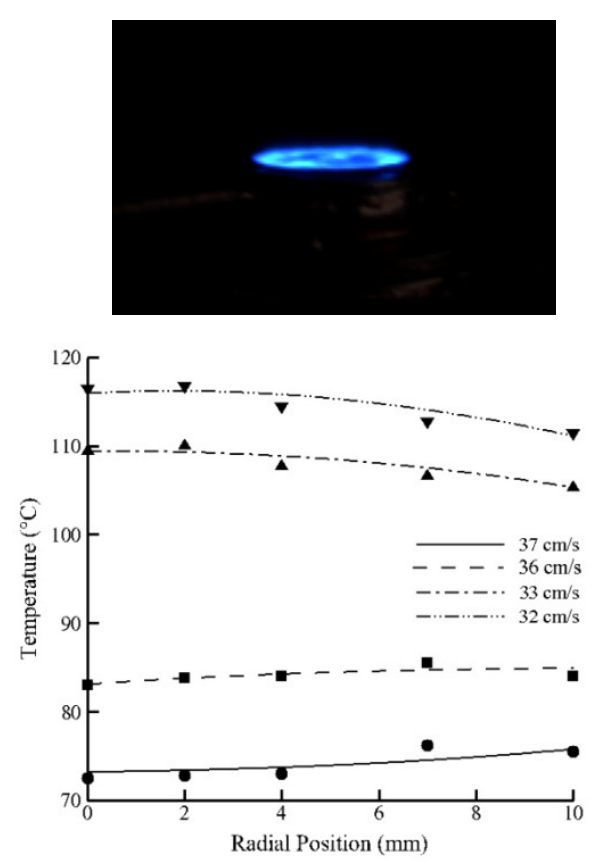

Fig. 4. Flame photo and temperature distribution of methane-air mixture
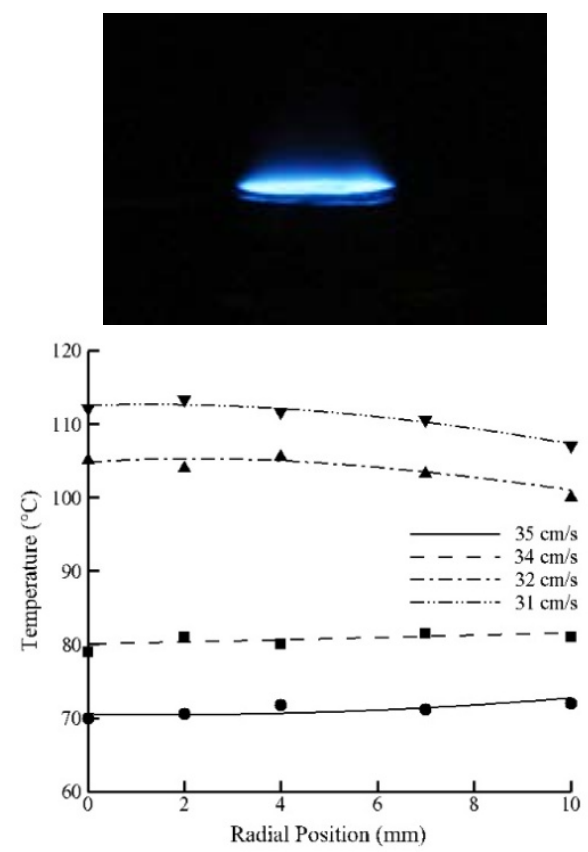

Fig. 5. Flame photo temperature distribution of diluted methane-air mixture with nitrogen

Flame photos of methane-air mixture and diluted mixture with nitrogen at $\phi=1$ besides of their temperature distribution data in burner plate are shown in Figs. 4 and 5. As mentioned before, the velocities that are assumed lower than adiabatic velocities are defined as sub-adiabatic conditions, for instance 32 and $33 \mathrm{~cm} / \mathrm{s}$ burning velocities in Fig. 4 and the velocities which are higher than adiabatic velocity are under super-adiabatic conditions, for example $37 \mathrm{~cm} / \mathrm{s}$ burning velocity in Fig. 4 . 


\section{The Effects of Dilution on Burning Velocity}

Effect of dilution of Methane-air mixture with nitrogen and carbon dioxide experimentally and with hydrogen numerically on laminar burning velocity in terms of equivalence ratio have been studied. All the additions and dilutions in the present work are expressed as a fraction of fuel mixture. For example, 20 percent dilution with $\mathrm{CO}_{2}$ means that the fuel is a gas mixture containing 80 percent methane and 20 percent $\mathrm{CO}_{2}$ by volume. The air used is 21 percent $\mathrm{O}_{2}$ and 79 percent $\mathrm{N}_{2}$ and the relative proportion of air in the fuel-air mixture is defined by the equivalence ratio. Measured adiabatic burning velocities of methane-air with $\mathrm{CO}_{2}, \mathrm{~N}_{2}$ and $\mathrm{H}_{2}$ dilution in fuel are plotted respectively in Figs. 6-8.

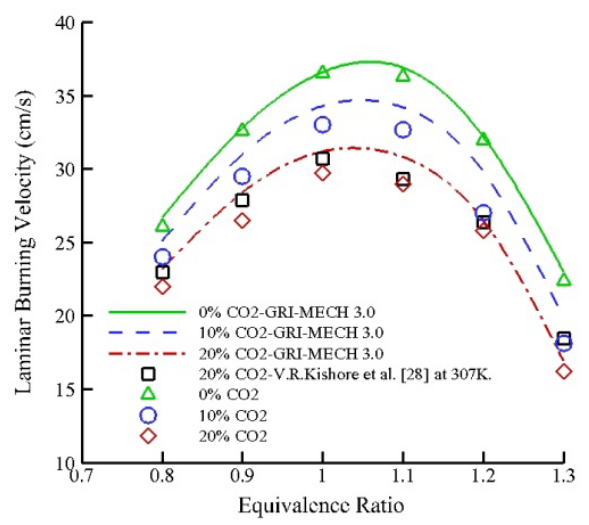

Fig. 6. Laminar burning velocities plotted against the equivalence ratio for $\mathrm{CH}_{4}-\mathrm{CO}_{2}$-air mixtures at $\mathrm{P}_{\text {ini }}=0.1 \mathrm{MPa}$ and $\mathrm{T}_{\text {ini }}=298 \mathrm{~K}$.Lines represent calculations with CHEMKIN and Symbols represent experimental data.

In Fig. 6, the effect of 10 and 20 percent dilution of Methane-air mixture with carbon dioxide on laminar burning velocity in $\mathrm{P}_{\mathrm{ini}}=0.1 \mathrm{MPa}$ and $\mathrm{T}_{\mathrm{ini}}=298 \mathrm{~K}$ has been shown in numerical and experimental methods, It is then compared with experimental data obtained from 20 percent dilution by Kishore et al. [28]. In Fig. 7, the effect of 10 and 20 percent dilution of Methane-air mixture with nitrogen on laminar burning velocity in $\mathrm{P}_{\text {ini }}=0.1 \mathrm{MPa}$ and $\mathrm{T}_{\mathrm{ini}}=298 \mathrm{~K}$ has been shown in numerical and experimental methods. Also, Fig. 8 shows calculated velocities for diluted Methane-air mixture with 10 and 20 percent hydrogen and Obtained results have been compared with experimental data of Halter et al. [29] and they show good agreements. When hydrogen is added to the mixture, burning velocity increases, the same behavior was found by Yu et al. [12]. However, their experimental burning velocities are higher than the present ones, even for pure methane-air mixtures. The results of Yu et al. [12] are probably too high due to the experimental configuration of their counter-flow burner.

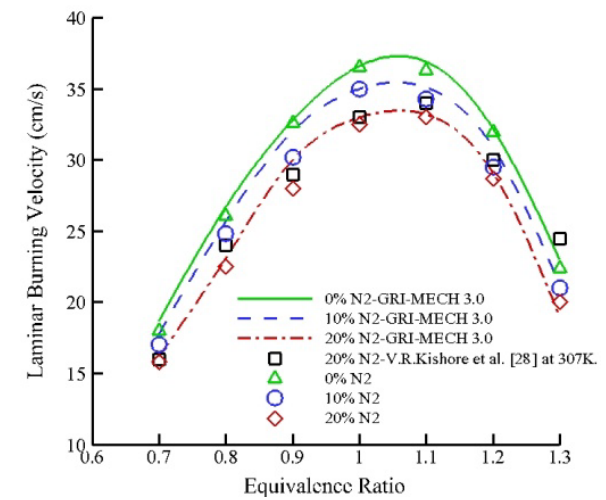

Fig. 7. Laminar burning velocities plotted against the equivalence ratio for $\mathrm{CH}_{4}-\mathrm{N}_{2}$-air mixtures at $\mathrm{P}_{\text {ini }}=0.1 \mathrm{MPa}$ and $\mathrm{T}_{\text {ini }}=298 \mathrm{~K}$. Lines represent calculations with CHEMKIN and Symbols represent experimental data.

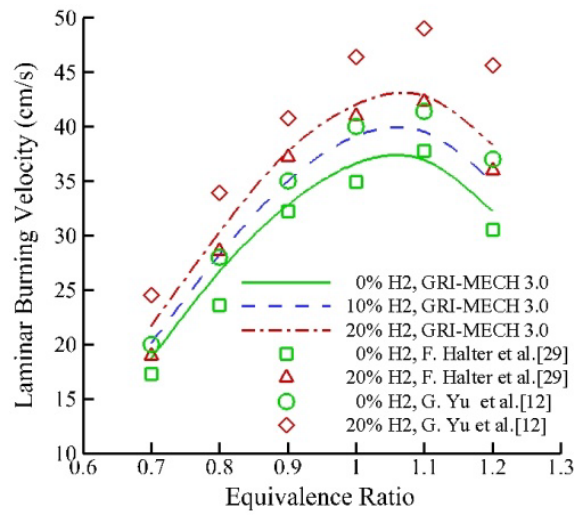

Fig. 8. Laminar burning velocities plotted against the equivalence ratio for $\mathrm{CH}_{4}-\mathrm{H}_{2}$-air mixtures at $\mathrm{P}_{\text {ini }}=0.1 \mathrm{MPa}$ and $\mathrm{T}_{\text {ini }}=298 \mathrm{~K}$. Lines represent calculations with CHEMKIN and Symbols represent experimental data.

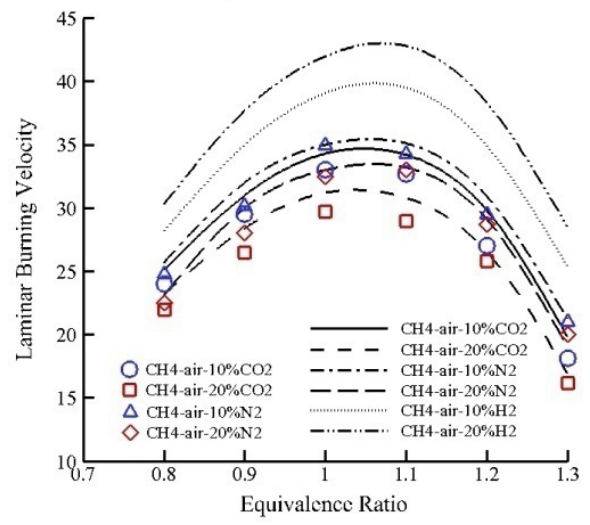

Fig. 9. Effect of $10 \%$ and $20 \%$ of $\mathrm{CO}_{2}, \mathrm{~N}_{2}$ and $\mathrm{H}_{2}$ dilution on laminar burning velocity of methane-air mixtures at $\mathrm{P}_{\text {ini }}=0.1 \mathrm{MPa}$ and $\mathrm{T}_{\mathrm{ini}}=298$

$\mathrm{K}$. Lines represent calculations with CHEMKIN and Symbols represent experimental data.

Results show that diluting Methane-air mixture with carbon dioxide and nitrogen decreases laminar burning velocity of premixed Methane-air mixture, while diluting this mixture with hydrogen has a reverse result with these two conditions and increases laminar burning velocity of premixed Methane-air mixture. In fact, hydrogen is one of 
the best options for natural gas, in order to increase the burning velocity and we expect the mixture of natural gas and hydrogen to improve features of lean combustion and decrease polluting emissions of motors [30, 31] (particularly $\mathrm{HC}$ and $\mathrm{CO}$ ). All calculated conditions are shown in Fig. 9 and it is noticeable that for the methane-air mixture, the maximum value of the laminar burning velocity is presented at near-stoichiometric mixture also, Reduction of burning velocity is less in lean side than at stoichiometric and rich side.

The laminar burning velocity decreases with the increase of the dilution ratio for both $\mathrm{N}_{2}$ and $\mathrm{CO}_{2}$ dilution. Dilution by $\mathrm{CO}_{2}$ gives larger reduction in burning velocity compared to $\mathrm{N}_{2}$. This behavior of burning velocity reduction can be attributed to the higher specific heat of $\mathrm{CO}_{2}$ in comparison to $\mathrm{N}_{2}$. Measurements and calculations of burning velocities were in reasonably good agreement for lean to moderately rich mixtures (i.e., up to $\phi=1.3$ ), for different concentrations of the diluents.

\section{The Effects of Pressure on Burning Velocity}

The effect of increasing pressure on laminar burning velocity of Methane-air mixture with 10 and 20 percent dilutions with carbon dioxide, hydrogen and nitrogen in different equivalence ratios has been shown in Figs. 10-12, respectively. The results of increasing pressure in three conditions of $0.1,0.3$ and $0.5 \mathrm{MPa}$ are presented. Results show that in all conditions of experimented dilutions, increasing pressure decreases velocity. The variation of the unstretched laminar burning velocity with pressure can be expressed through the empirical expression [32]:

$$
S_{L}=S_{L}^{0}\left(\frac{T_{u}}{T_{0}}\right)^{a_{T}}\left(\frac{P_{u}}{P_{0}}\right)^{b_{p}}
$$

Where $S_{L}^{0}$ is the unstretched laminar burning velocity for a pressure $P_{0}$ and a temperature $T_{0}$, the parameters $a_{T}$ and $b_{p}$ depend upon $\phi$.

In Figs. 10 and 11, the laminar burning velocities measured (symbols) and calculated (lines) for mixtures diluted with carbon dioxide and nitrogen are plotted. A similar pressure dependence to the one obtained for diluted mixtures are observed. When the pressure increases, the laminar burning velocity decreases both for diluted methane-air mixture with carbon dioxide and nitrogen. The agreement between measurements and calculations is good, especially for atmospheric pressure. A similar trend is seen for diluted methane-air mixture with hydrogen which is calculated and plotted in Fig. 12. The pressure effect on the flame thickness calculated by numerical method for methane-air mixtures is shown in Fig. 13. The laminar flame thickness decreases when the pressure increases. The influence of the equivalence ratio is almost the same at atmospheric pressure and for $0.5 \mathrm{MPa}$ (decrease of 33 percent between equivalence ratios of 0.8 and 1.0 both at 0.1 and $0.5 \mathrm{MPa}$ ).

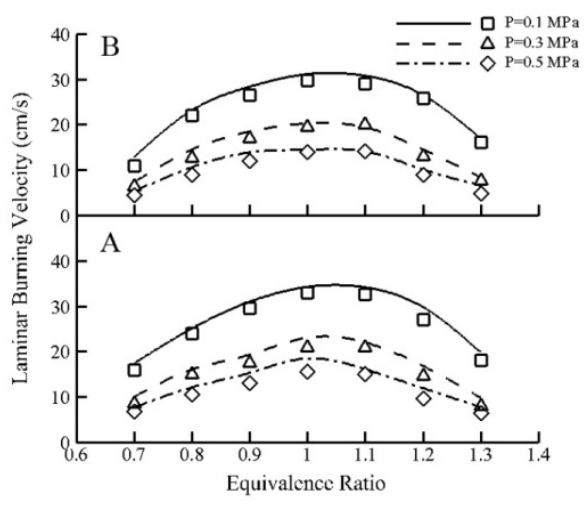

Fig. 10. Laminar burning velocities plotted against the equivalence ratio for $\mathrm{CH}_{4}-\mathrm{CO}_{2}$-air mixtures at $\mathrm{T}_{\text {ini }}=298 \mathrm{~K}$. (A) $10 \%$ dilution. (B) $20 \%$ dilution. Lines represent calculations with CHEMKIN and Symbols represent experimental data.

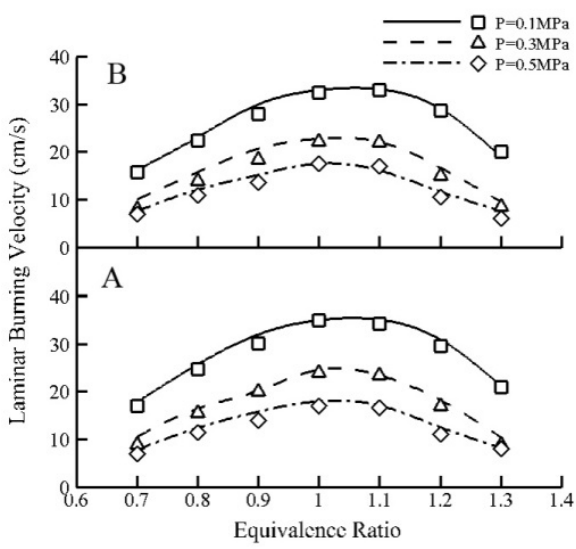

Fig. 11. Laminar burning velocities plotted against the equivalence ratio for $\mathrm{CH}_{4}-\mathrm{N}_{2}$-air mixtures at $\mathrm{T}_{\text {ini }}=298$. (A) $10 \%$ dilution. (B) $20 \%$ dilution. Lines represent calculations with CHEMKIN and Symbols represent experimental data.

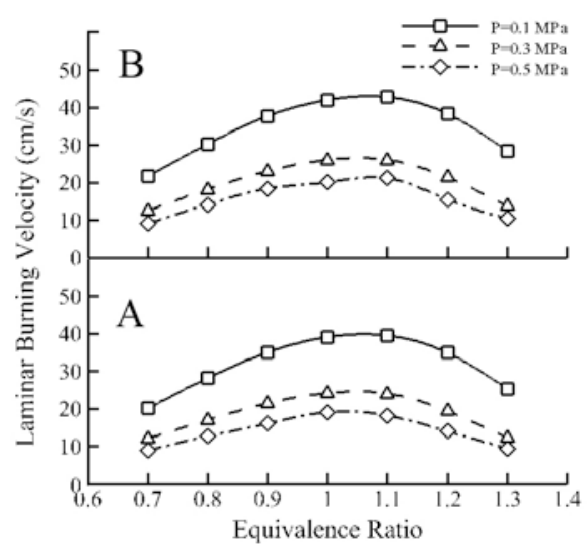

Fig. 12. Numerically calculated Laminar burning velocities plotted against the equivalence ratio for $\mathrm{CH}_{4}-\mathrm{H}_{2}$-air mixtures at $\mathrm{T}_{\text {ini }}=298$.

(A) $10 \%$ dilution. (B) $20 \%$ dilution.

\section{The Effects of Pressure and Dilution on NO formation}

Study of combustion mechanism resulted from adding diluents such as carbon dioxide, nitrogen and hydrogen to Methane and decreasing $\mathrm{NO}_{\mathrm{x}}$, is one the most important topics in combustion. Literature shows that concentration of 
$\mathrm{NO}_{\mathrm{x}}$ resulted from Methane combustion, increases by adding hydrogen, especially in high ratios [33-35]. Also, in constant equivalence ratio, adding hydrogen to Methane-air flame increases the flame temperature significantly [36]. The combustion of fuels that contain no nitrogen, nitric oxide (NO) is formed by three chemical mechanisms or routes that involve nitrogen from the air. They are thermal or Zeldovich mechanism, prompt or Fenimore mechanism, and $\mathrm{N}_{2} \mathrm{O}$-intermediate mechanism [37].

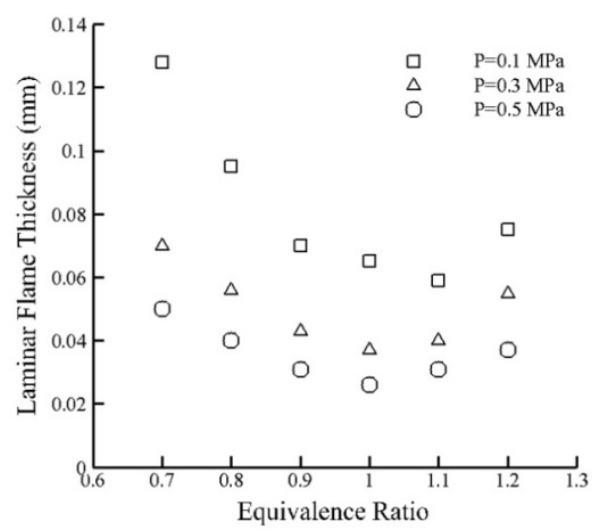

Fig. 13. Numerically calculated Laminar flame thickness plotted against the equivalence ratio for $\mathrm{CH}_{4}$-air mixtures at $\mathrm{T}_{\text {ini }}=298 \mathrm{k}$.

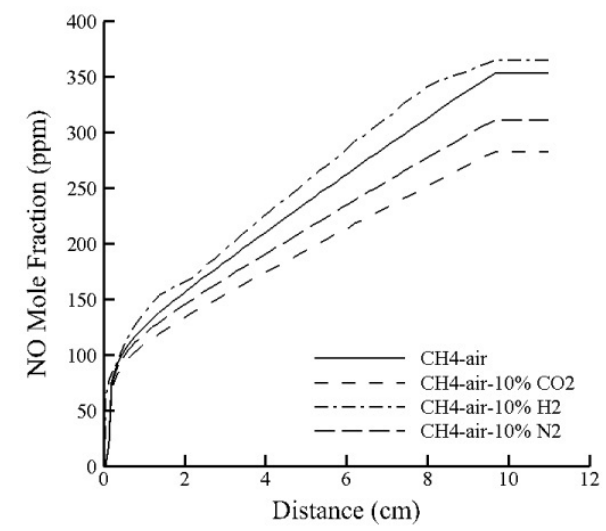

Fig. 14. Calculated NO mole fraction of methane-air flame diluted with $10 \%$ of $\mathrm{CO}_{2}, \mathrm{H}_{2}$ and $\mathrm{N}_{2}$ versus distance at $\phi=1, \mathrm{P}_{\text {ini }}=0.1 \mathrm{MPa}$ and $\mathrm{T}_{\mathrm{ini}}=298 \mathrm{~K}$.

Thermal mechanism dominates in high-temperature combustion over a wide range of equivalence ratios, while prompt mechanism is particularly important in fuel-rich combustion. It appears that the $\mathrm{N}_{2} \mathrm{O}$ intermediate mechanism plays an important role in the production of $\mathrm{NO}$ in the high lean and low-temperature combustion process. Figs. 14 and 15 show mole fraction of NO resulted from numerical solution of adding 10 and 20 percent carbon dioxide, hydrogen and nitrogen to Methane-air fuel mixture, in initial pressure of 1 atmosphere, initial temperature of $298 \mathrm{~K}$ and in stoichiometric condition in terms of distance from the burner. In Fig. 16, all conditions of these two studies are presented.

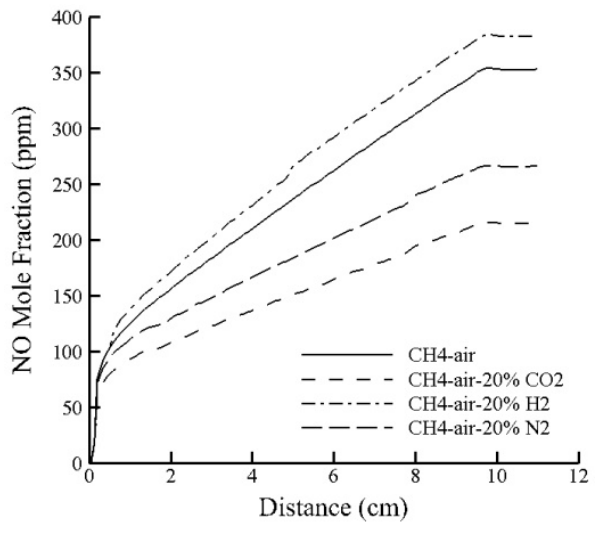

Fig. 15. Calculated NO mole fraction of methane-air flame diluted with $20 \%$ of $\mathrm{CO}_{2}, \mathrm{H}_{2}$ and $\mathrm{N}_{2}$ versus distance at $\phi=1, \mathrm{P}_{\text {ini }}=0.1 \mathrm{MPa}$ and $\mathrm{T}_{\text {ini }}=298 \mathrm{~K}$.

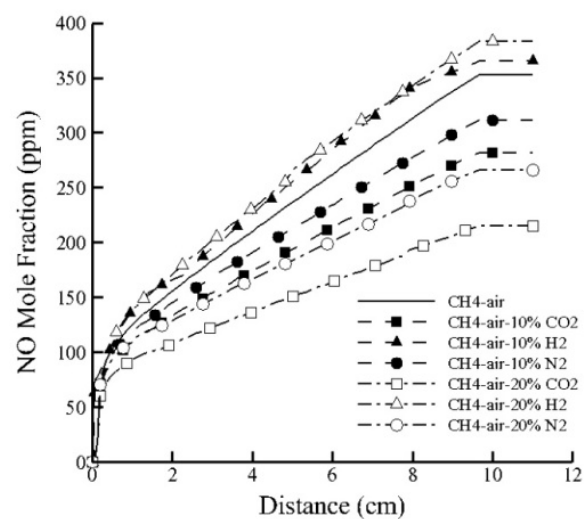

Fig. 16. Calculated NO mole fraction of methane-air flame diluted with $10 \%$ and $20 \%$ of $\mathrm{CO}_{2}, \mathrm{H}_{2}$ and $\mathrm{N}_{2}$ versus distance at $\phi=1, \mathrm{P}_{\text {ini }}=0.1 \mathrm{MPa}$ and $\mathrm{T}_{\mathrm{ini}}=298 \mathrm{~K}$.

In the case of $\phi=1$, Formation of $\mathrm{NO}$ is almost completed at the distance greater than $10 \mathrm{~cm}$ from the flame front due to the Zeldovich thermal-NO mechanism. Because of the high flame temperature near the stoichiometric mixtures, the NO formation is resulted from the Thermal NO mechanism. While in fuel-rich flames, there are a lot of $\mathrm{CH}$ radicals in the flame front and the flame temperature is lower, so NO formation is resulted from the Fenimore prompt-NO mechanism which occurs within the flame front [38]. From Figs 14 to 16, we can conclude that adding carbon dioxide and nitrogen to Methane-air fuel mixture, decreases NO formation, however, increasing in NO formation is seen by adding hydrogen to methane-air mixture. By adding 10, 20 percent carbon dioxide and nitrogen, the most decrease in NO formation is related to adding $20 \%$ carbon dioxide. This decrease is apparently due to flame temperature decrease. With the increase of hydrogen fraction, the adiabatic flame temperature is increased and it induces the mechanism to be active as a result it causes NO formation increase. 


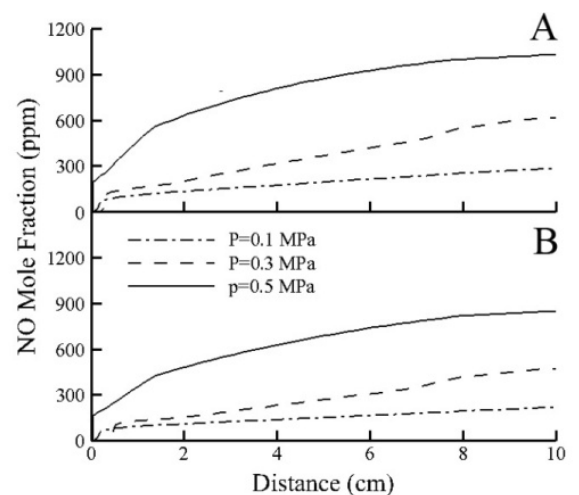

Fig. 17. Calculated NO mole fraction of methane-air flame diluted with $\mathrm{CO}_{2}$ at $\mathrm{P}=0.1,0.3$ and $0.5 \mathrm{MPa}$ versus distance at $\phi=1$, $\mathrm{T}_{\mathrm{ini}}=298 \mathrm{~K}$. (A) $10 \%$ dilution. (B) $20 \%$ dilution.

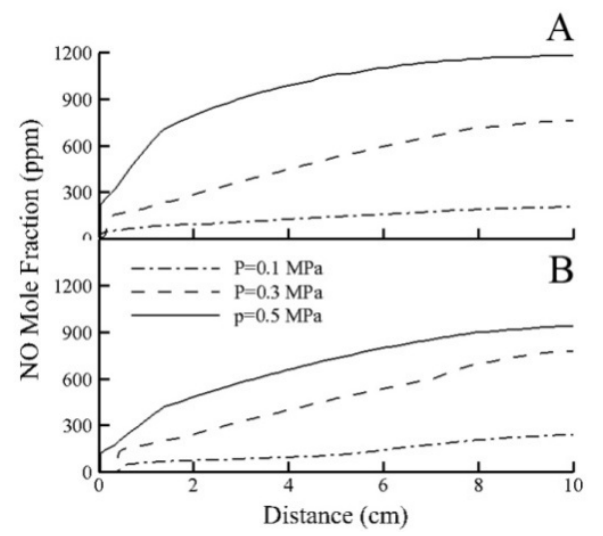

Fig. 18. Calculated NO mole fraction of methane-air flame diluted with $\mathrm{N}_{2}$ at $\mathrm{P}=0.1,0.3$ and $0.5 \mathrm{MPa}$ versus distance at $\phi=1, \mathrm{~T}_{\mathrm{i}-}$ ni $=298 K$. (A) $10 \%$ dilution. (B) $20 \%$ dilution.

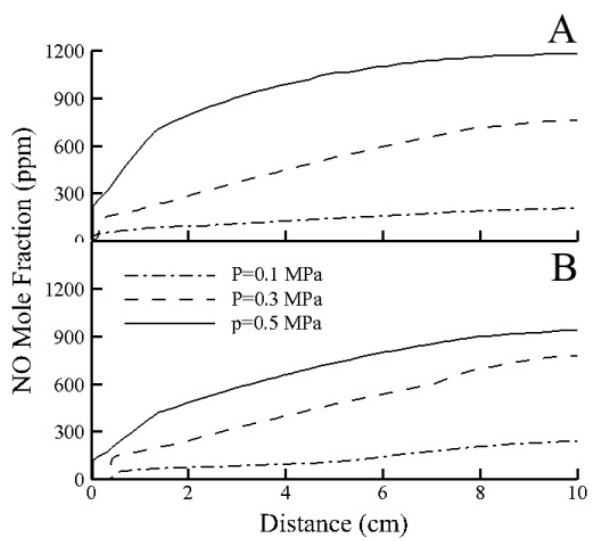

Fig. 19. NO calculated mole fraction of methane-air flame diluted with $\mathrm{H}_{2}$ at $\mathrm{P}=0.1,0.3$ and $0.5 \mathrm{MPa}$ versus distance at $\phi=1, \mathrm{~T}_{\text {ini }}=298 \mathrm{~K}$. (A) $10 \%$ dilution. (B) $20 \%$ dilution.

Finally, we study numerically the effect of increasing pressure from 1 to 5 atmospheres on NO formation of Methane-air fuel mixture diluted with carbon dioxide, hydrogen and nitrogen in stoichiometry condition. Few experimental and numerical studies have been done about the NO formation in premixed flames in different pressure [39, 40]. In Fig. 17, the effect of increasing pressure on
Methane-air mixture diluted with 10 and 20 percent $\mathrm{CO}_{2}$ is shown. Also, Figs. 18 and 19 show the study of increasing nitrogen and hydrogen respectively. Results show that in high pressures, NO formation increases, and in $10 \%$ increase of diluents, NO formation is more than that in $20 \%$ increase of diluents. Temperature profiles are strongly dependent upon pressure, when the temperature changes, the rate of the reaction increases [41], which results in observed growth of the calculated NO mole fractions with pressure.

\section{Conclusion}

In this paper, the focus was on the effects of adding carbon dioxide, hydrogen and nitrogen as well as increasing pressure on laminar burning velocity of Methane-air mixture and NO formation. Laminar burning velocity was studied experimentally through the Heat Flux method, also numerically with the use of PREMIX code in CHEMKIN package which was used to simulate progression of laminar flame combustion has the required efficiency in diluting and pressure increasing in premixed mixtures. Good agreement was observed between results of dilution by numerical and experimental solutions and results of experimental studies in previous papers. Increasing hydrogen increases velocity of combustion, while increasing carbon dioxide and nitrogen indicate decrease of laminar burning velocity. Reduction of $\mathrm{NO}$ formation by adding $\mathrm{N}_{2}$ or $\mathrm{CO}_{2}$ to the methane-air mixture is seen to be caused by flame temperature decrease, by contrast, the addition of $\mathrm{H}_{2}$ induces the mechanism to be active due to high temperature flame and it brings NO formation growing up.

When initial pressure increases, combustion velocity decreases for all mixtures and NO increases reactions. At higher pressures, flame temperature increases and as a result NO mole fraction grows up, moreover, increasing pressure decreases flame thickness for Methane-air mixture. When the pressure increases, the fundamental burning velocity decreases for mixtures, as well as the laminar flame thickness. The version of the CHEMKIN package used succeeds to some extent in simulating the evolution of laminar burning velocity when hydrogen, nitrogen and carbon dioxide are added and when pressure is increased, however, it needs to be improved before it gives the correct values.

\section{Nomenclature}

$c_{p i} \quad$ : Specific heat capacity at constant pressure of species $i$

g : Gravity acceleration

$h_{i} \quad:$ Enthalpy of species $i$

$h_{i}^{\text {ref }} \quad$ : Formation enthalpy of species $i$

I : Unit tensor

$M_{i} \quad$ : Molar mass of species $i$

$\bar{M} \quad$ : Mean molar mass 


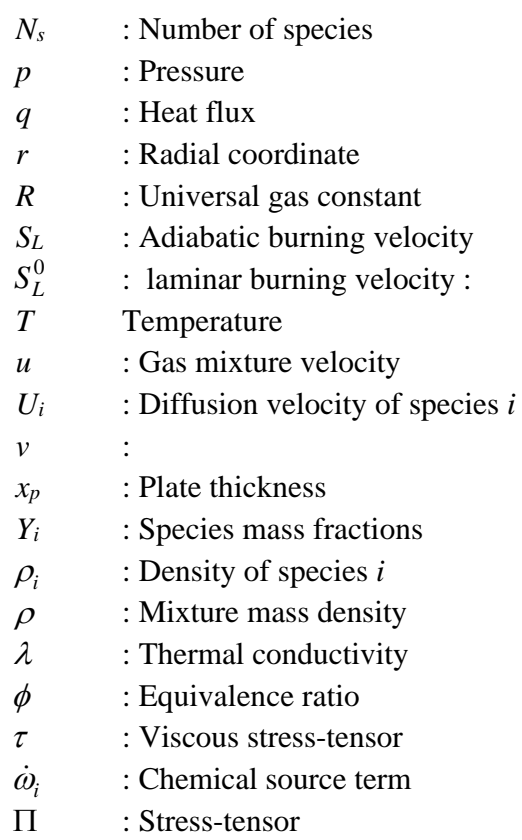

\section{References}

[1] O. Riccius, R. Smith, F. Guthe and P. Flohr, The GT24/26 combustion technology and high hydrocarbon fuels, Proc. of ASME Turbo Expo Power for Land, Sea and Air, Reno 2005.

[2] G. Iskender and E. Lebas, Alternative fuels for industrial gas turbines, Applied Thermal Engineering, 24 (11-12) (2004) 1655-1663.

[3] X. Zhang, , B. W. Wang, , Y. W. Liu and G. H. Xu, Conversion of methane by steam reforming using dielectric-barrier discharge, Chinese Journal of Chemical Engineering, 17 (4) (2009) 625-629.

[4] C. Shanshan, J. Yong, Q. Rong and A. Jiangtao, Numerical study on laminar burning velocity and flame stability of premixed Methane/Ethylene/Air flames, Chinese Journal of Chemical Engineering, 20 (2) (2012) 914-922.

[5] A. Bilgin, Geometric features of the flame propagation process for an SI engine having dual ignition system, International Journal of Energy Research, 26 (11) (2002) 987-1000.

[6] E. Hu, X. Jiang, Z. Huang and N. Iida, Numerical study on the effects of diluents on the laminar burning velocity of Methane-Air mixtures, Energy and Fuels, 26 (7) (2012) 4242-4252.

[7] A. Clarke, R. Stone and P. Beckwith, Measuring the laminar burning velocity of methane/diluent/air mixtures within a constant-volume combustion bomb in a microgravity environment, Journal of Energy Institute, 68 (476) (1995) 130-136.

[8] A. Van Maaren, D. S. Thung and L. P. H. De Goey, Measurement of flame temperature and adiabatic burning velocity of methane/air mixtures, Combustion Science and Technology, 96 (4) (1994) 327-344.

[9] E. J. Hu, Z. H. Huang, B. Liu, J. J. Zheng and X. L. Gu, Experimental study on combustion characteristics of a spark-ignition engine fueled with natural gas-hydrogen blends combining with EGR, International Journal of Hydrogen Energy, 34 (2) (2009) 1035-1044.

[10] R. T. E. Hermanns, J. A. Kortendijk, R. J. M. Bastiaans and L. P. H. De Goey, Laminar burning velocities of methane-hydrogen-air mixtures, Third European Conference on Small Burner Technology and Heating Equipment, (2003) 240-247.

[11] R. T. E. Hermanns, Laminar burning velocities of methane-hydrogen-air mixtures, $\mathrm{PhD}$ Thesis, Eindhoven University of Technology, (2007).

[12] G. Yu, C. K. Law and C. K. Wu, Laminar flame speeds of hydrocarbon air mixtures with hydrogen addition, Combustion and Flame, 63 (3) (1986) 339-347.

[13] K. J. Bosschaart, L. P. H. de Goey, Detailed analysis of the heat flux method for measuring burning velocities, Combustion and Flame, 132 (1-2) (2003) 170-180.

[14] A. Van Maaren, D. S. Thung and L. P. H. de Goey, Measurement of flame temperature and adiabatic burning velocity of methane/air mixtures, Combustion Science and Technology, 96 (1994) 327-344.

[15] I. V. Dyakov, A. A. Konnov, J. Ruyck, K. J. Bosschaart, E. C. M. Brock and L. P. H. de Goey, Measurement of adiabatic burning velocity in methane-oxygen-nitrogen mixtures, Combustion Science and Technology, 172 (1) (2001) 81-96.

[16] K. J. Bosschaart and L. P. H. de Goey, The laminar burning velocity of mixtures of hydrocarbon and air as measured with the heat-flux method, Combustion and Flame, 136 (3) (2004) 261-269.

[17] A. A. Konnov, R. J. Meuwissen and L. P. H. de Goey, The temperature dependence of the laminar burning velocity of ethanol flames, Proc. of the Combustion Institute, 33 (1) (2011) 1011-1019.

[18] L. P. H. de Goey, L. M. T. Somers, W. M. L. Bosch and R. M. M. Mallens, Modeling of small scale structure of flat burner-stabilized flames, Combustion Science and Technology, 104 (1995) 387-400

[19] R. J. Kee, J. F. Grcar, M. D. Smooke and J. A. Miller, PREMIX: a FORTRAN program for modeling steady laminar one-dimensional premixed flames, Sandia National Laboratory, SAND Report, (1985) 85-8240.

[20] R. J. Kee, F. M. Rupley and J. A. Miller, CHEMKIN-II: a FORTRAN chemical kinetics package for the analysis of gas-phase chemical kinetics, Technical Report SAND, Sandia National Laboratories, (1989) 89-8009

[21] M. Frenklach, T. Bowman, G. Smith, B.Gardiner,. Available from: <http://www.me.berkeley.edu/gri_mech/>.

[22] F. N. Egolfopoulos, P. Cho and C. K. Law, Laminar flame speeds of methane/air mixtures under reduced and 
elevated pressures, Combustion and Flame, 76 (3-4) (1989) 375-391.

[23] C. Uykur, P. F. Henshaw, D. S. K. Ting and R. M. Barron, Effects of addition of electrolysis product on methane/air premixed laminar combustion, International Journal of Hydrogen Energy, 26 (3) (2001) 265-273.

[24] C. M. Vagelopoulos and F. N. Egolfopoulos, Direct experimental determination of laminar flame speeds, Symposium (International) on Combustion, 27 (1) (1998) 513-519.

[25] X. J. Gua, M. Z. Haqa, M. Lawesa and R. Woolleya, Laminar burning velocity and Markstein lengths of methane-air mixtures, Combustion and Flame, 121 (1-2) (2000) 41-58.

[26] F. Halter, T. Tahtouh and C. M. Rousselle, Nonlinear effects of stretch on the flame front propagation, Combustion and Flame, 157 (10) (2010) 1825-1832.

[27] O. Park, P. S. Veloo, N. Liu and F. N. Egolfopoulos, Combustion characteristics of alternative gaseous fuels, Proceedings of the Combustion Institute, 33 (1) (2011) 887-894.

[28] V. R. Kishore, N. Duhan, M. R. Ravi and A. Ray, Measurement of adiabatic burning velocity in natural gaslike mixtures, Experimental Thermal and Fluid Science, 33 (1) (2008) 10-16.

[29] F. Halter, C. Chauveau, N. D. Chaumeix and I. Gokalp, Characterization of the effects of pressure and hydrogen concentration on laminar burning velocities of methanehydrogen-air mixture, Proceedings of the Combustion Institute, 30 (1) (2005) 201-208.

[30] H. Erjiang, Z. Huang, J. Zheng, Q. Li and J. He, Numerical study on laminar burning velocity and NO formation of premixed methane-hydrogen-air flames, International Journal of Hydrogen Energy, 34 (15) (2009) 6545-6557.

[31] S. Lee, H. Lee, Y. Park and Y. Cho, Combustion and emission characteristics of HCNG in a constant volume chamber, Journal of Mechanical Science and Technology, 25 (2) (2011) 489-494.

[32] M. Metghalchi and J. C. Keck, Laminar burning velocity of propane /air mixtures at high temperature and pressure, Combustion and Flame, 38 (1980) 143-154.

[33] J. H. Wang, Z. H. Huang, Y. Fang, B. Liu, K. Zeng, H. Y. Miao and D. Jiang, Combustion behaviors of a direct injection engine operating on various fractions of natural gas-hydrogen blends, International Journal of Hydrogen Energy, 32 (15) (2007) 3555-3564.

[34] H. S. Guo, G. J. Smallwood, F. S. Liu, Y. G. Ju and O. L. Gulder, The effect of hydrogen addition on flammability limit and NOx emission in ultra-lean counterflow CH4/air premixed flames, Proc. of the Combustion Institute, 30 (2005) 303-311.

[35] K. Chun, H. Chung, S. Chung, J. Choi, A numerical study on extinction and NOx formation in nonpremixed flames with syngas fuel, Journal of Mechanical Science and Technology, 25 (11) (2011) 2943-2949.

[36] J. Y. Ren, W. Qin, F. N. Egolfopoulos and T. T. Tsotsis, Strain-rate effects on hydrogen-enhanced lean premixed combustion, Combustion and Flame, 124 (2001) 717-720.

[37] J. Warnatz, U. Maas, R. W. Dibble, Combustion: physical and chemical fundamentals, modeling and simulation, experiments, pollutant formation, 2nd ed. Berlin, Springer-Verlag 1998.

[38] S. M. Correa, A review of NOx formation under gasturbine combustion conditions, Combustion Science and Technology, 87 (1993) 329-362.

[39] P. V. Heberling, "Prompt no" measurements at high pressures, Symposium (International) on Combustion, 16 (1) (1977) 159-168.

[40] M. S. Klassen, D. D. Thomsen, J. R. Reisel and N. M. Laurendeau, Laser-induced fluorescence measurements of nitric oxide formation in high-pressure premixed methane flames, Combustion Science and Technology, 111 (1) (1995) 229-247.

[41] V. M. V. Essen, A. V. Sepman, A. V. Mokhov and H. B. Levinsky, Pressure dependence of NO formation in laminar fuel-rich premixed CH4/air flames, Combustion and Flame, 153 (3) (2008) 434-441. 